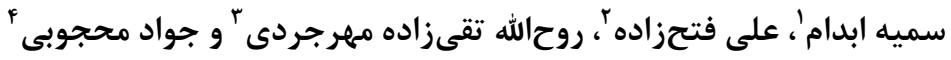

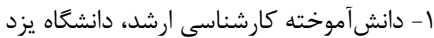

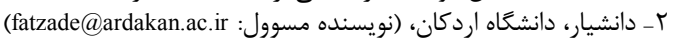

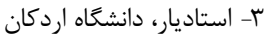

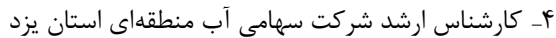

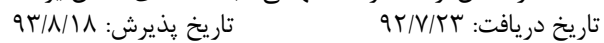

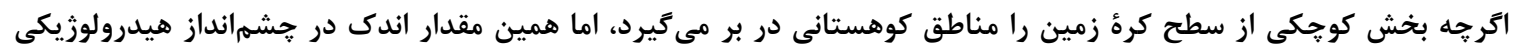

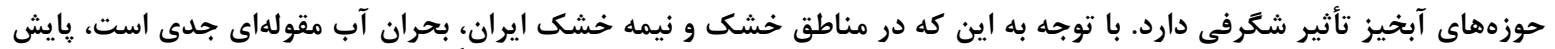

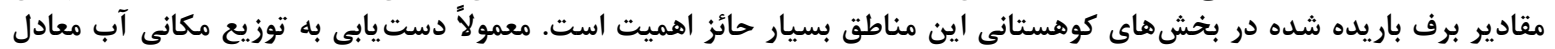

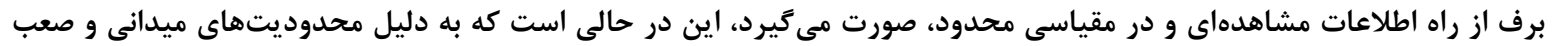

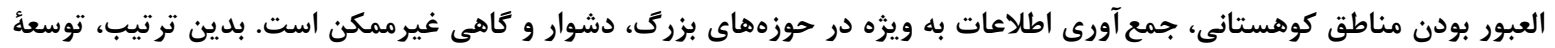

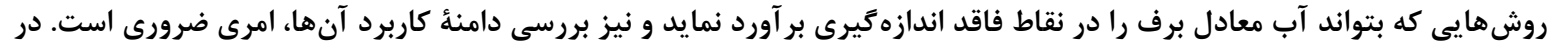

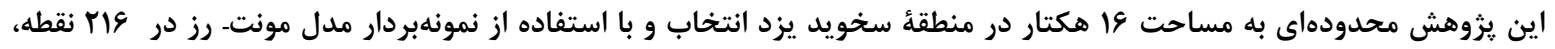

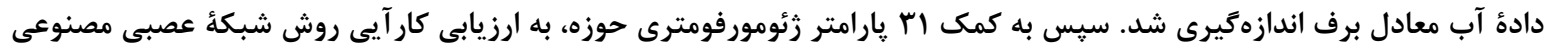

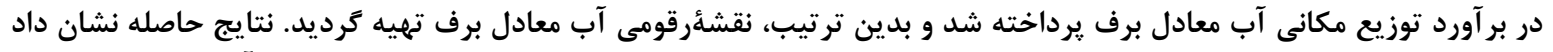

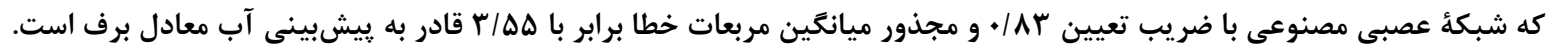

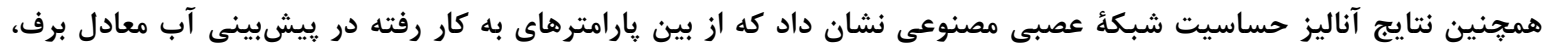

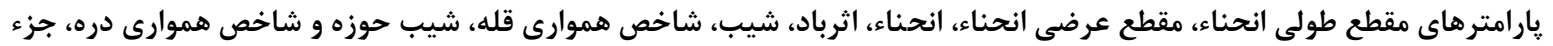

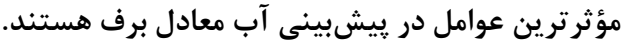

وازههاى كليدى: آب معادل برف، شبكهُ عصبى مصنوعى، آناليز حساسيت، پارامترهاى زئومرفومترى، حوزهُ آبخيز سخويد

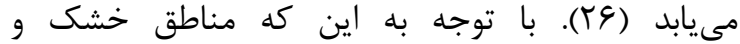

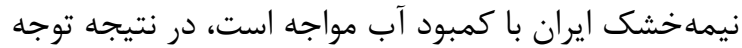

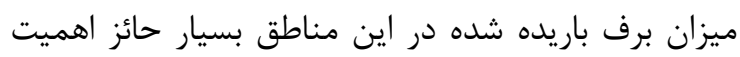

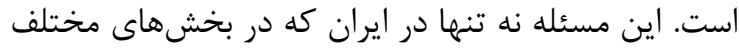

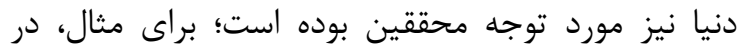

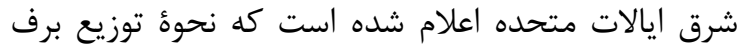

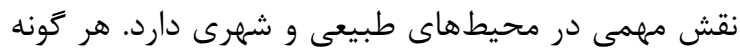

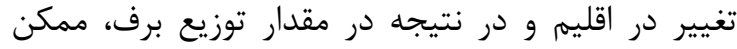

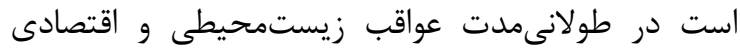

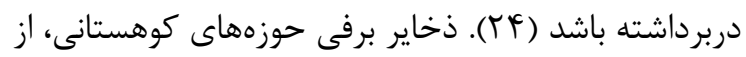

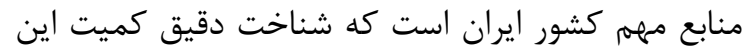

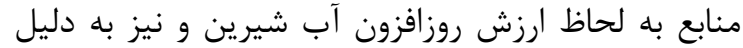

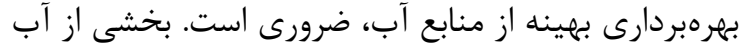

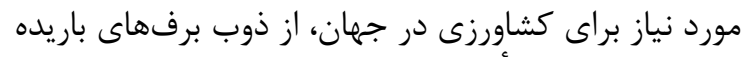

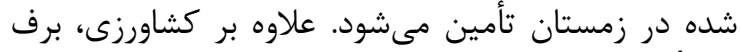

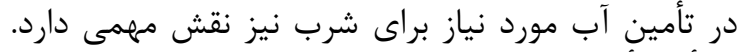

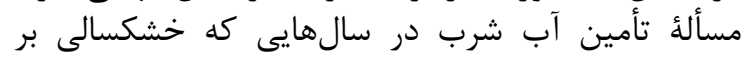

مقدمه

برف، يكى از انواع مختلف بارش است كه از جُالش

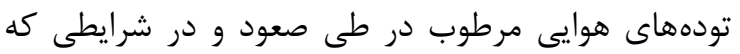

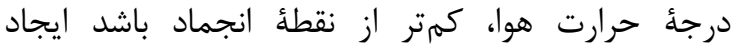

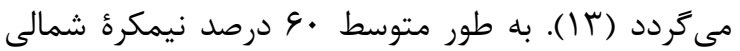

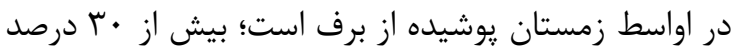

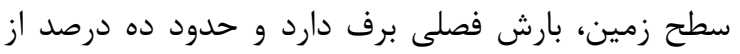

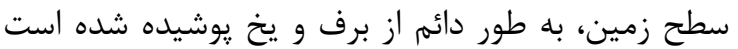

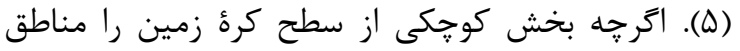

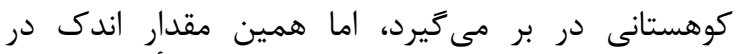

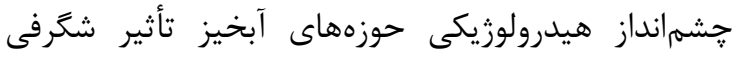

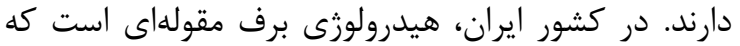

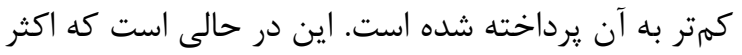

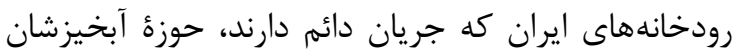

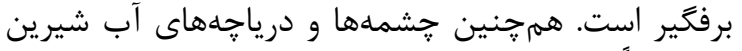

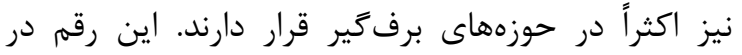

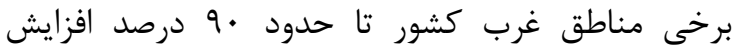


اعتمادتر و به هنكام در مورد برف با هزينهُ منطقى و ارتقاء

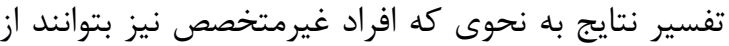

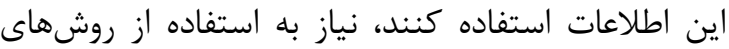

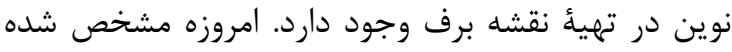

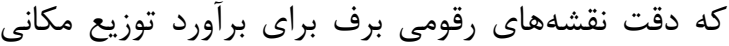

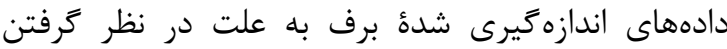

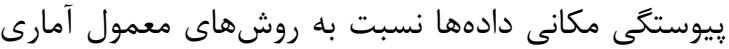

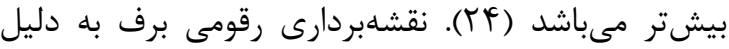

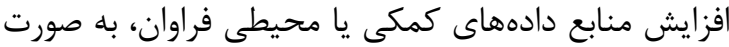

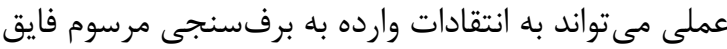

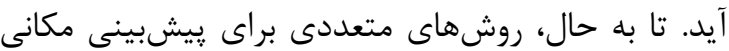

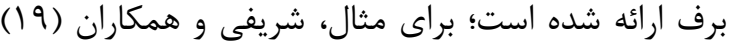

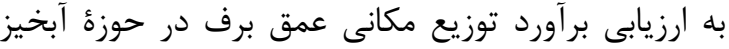

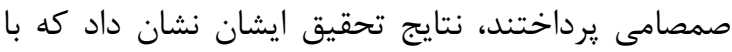

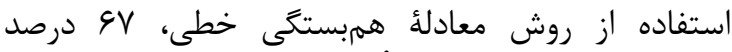

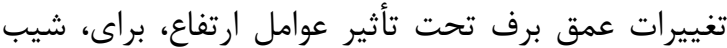

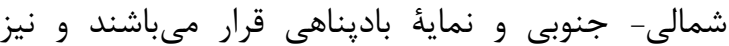

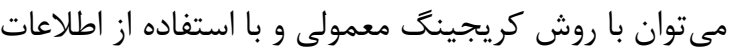

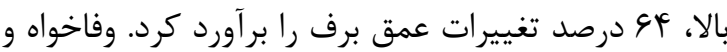

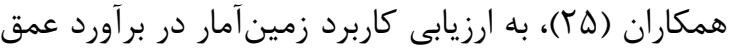

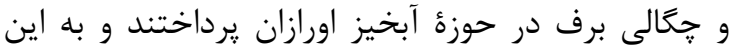

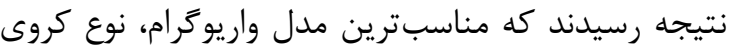

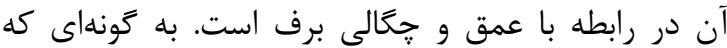

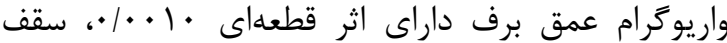

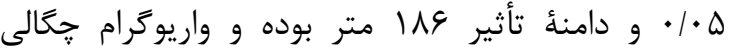

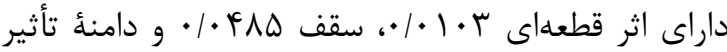

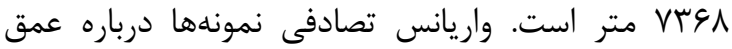

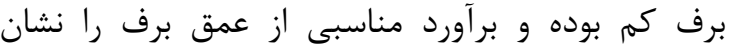

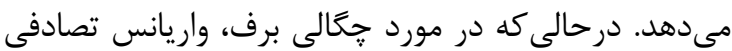

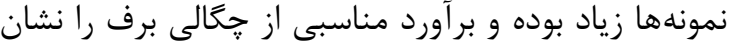

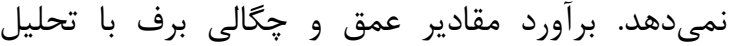

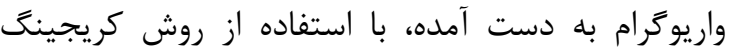

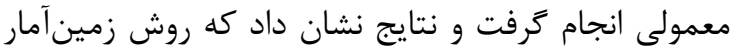

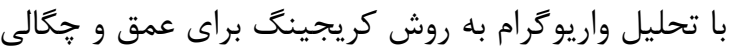

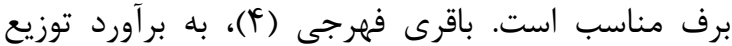

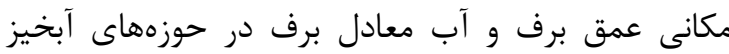

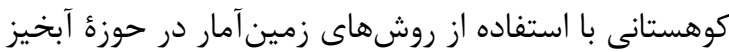

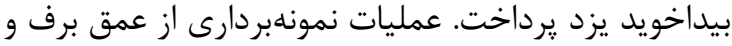

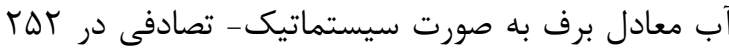

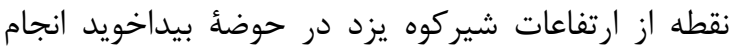

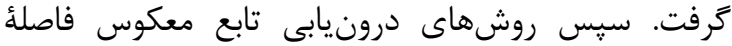

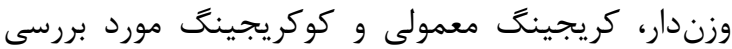

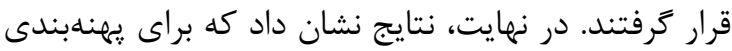

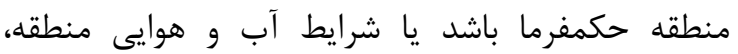

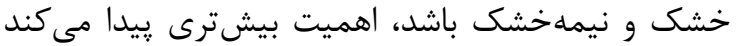

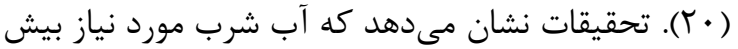

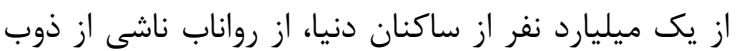

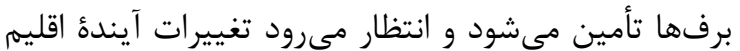

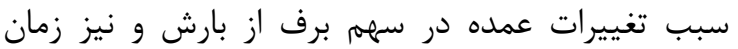

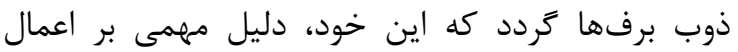

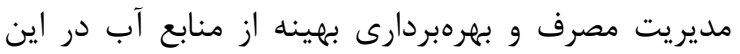

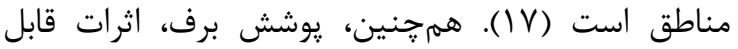

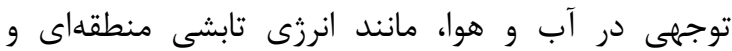

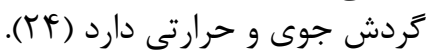

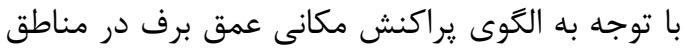

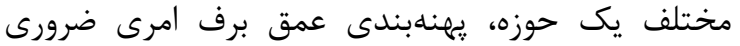

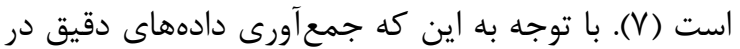

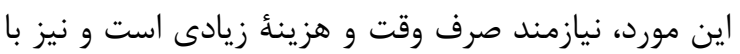

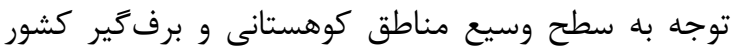

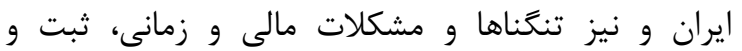

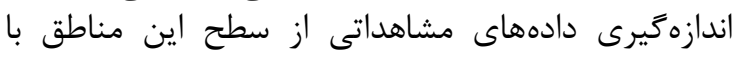

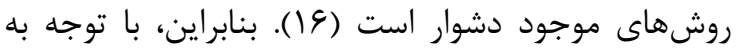

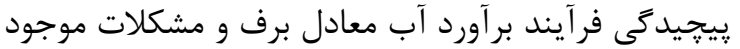

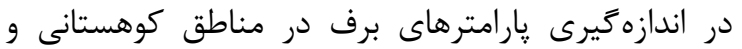

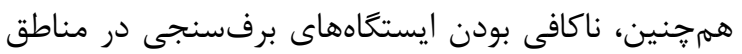

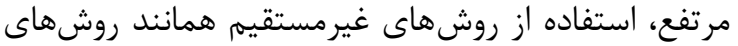

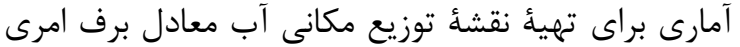
كريزنايذير است.

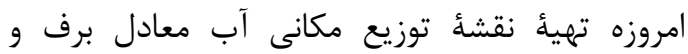

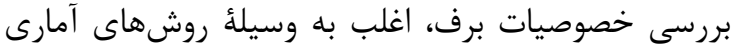

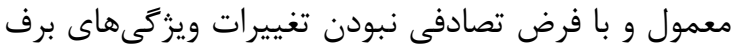

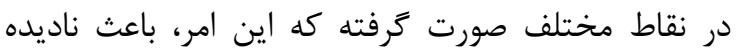

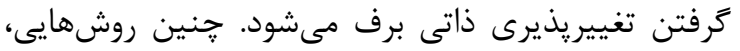

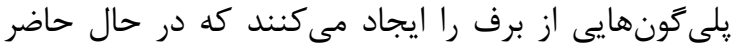

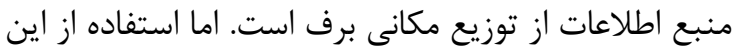

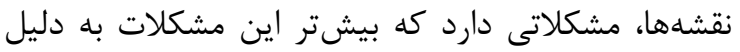

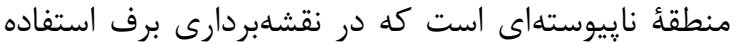

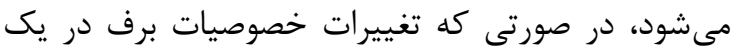

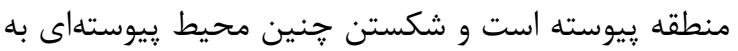

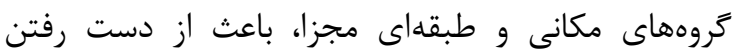

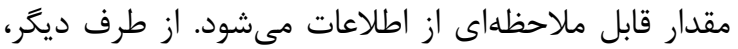

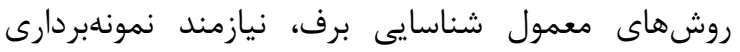

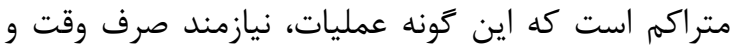
هزينه هاى فراوان است.

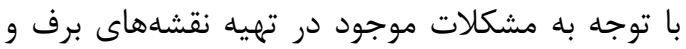

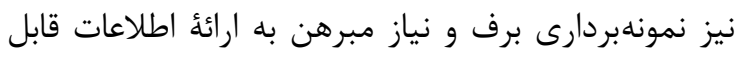


كليه اجزاء سرزمين صورت نخرفته است. رابر و همكاران

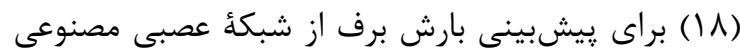

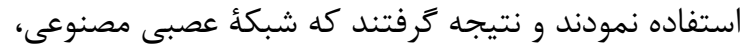

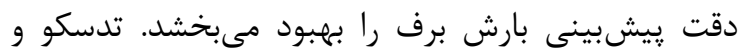

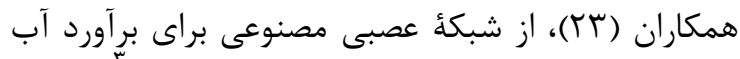

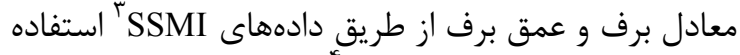

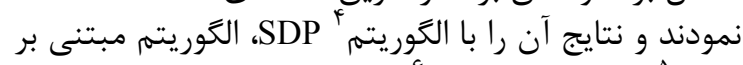

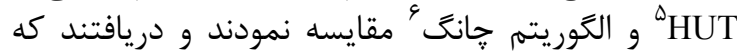

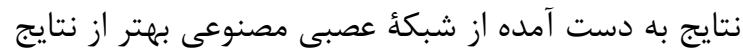

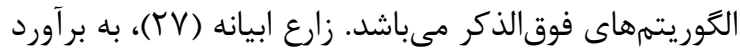

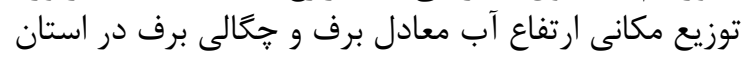

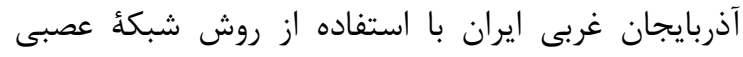

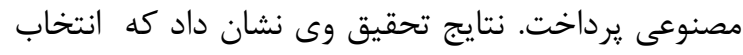

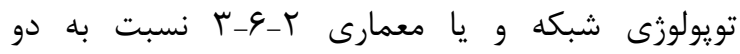

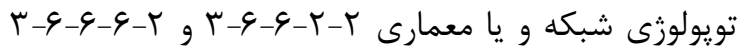

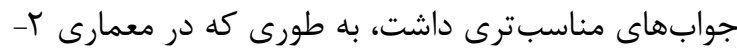

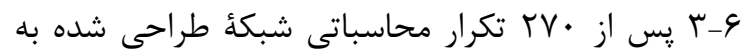

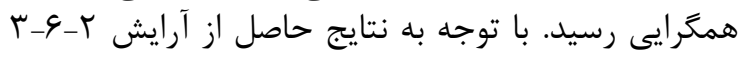

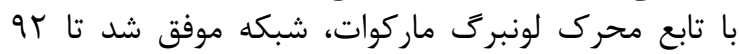

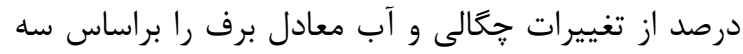

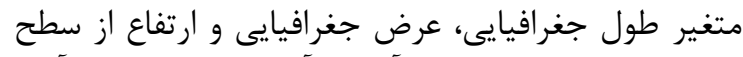

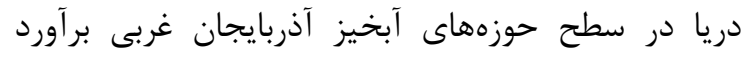

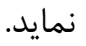

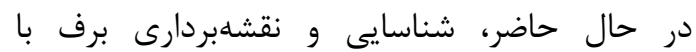

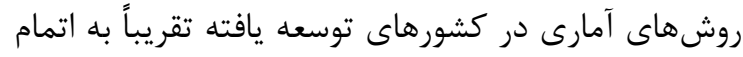

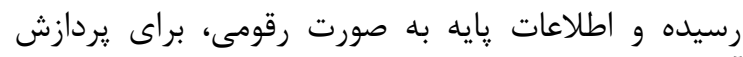

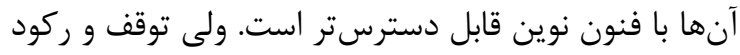

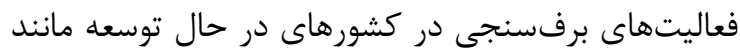

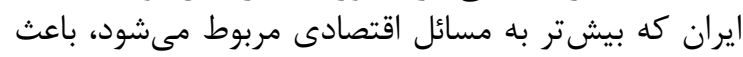

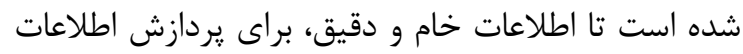

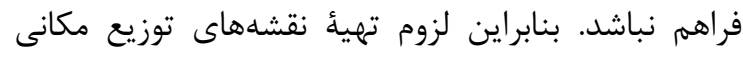

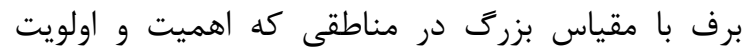

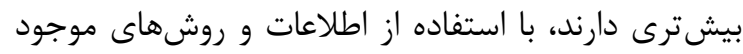

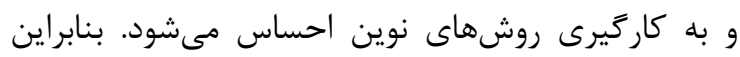

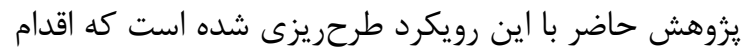

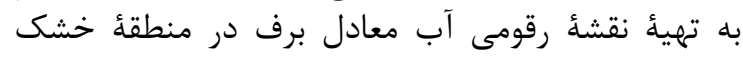

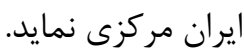

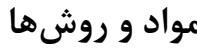
منطقة مورد مطالعه

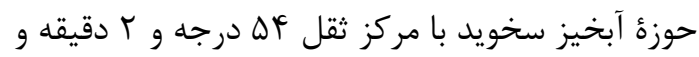
ها

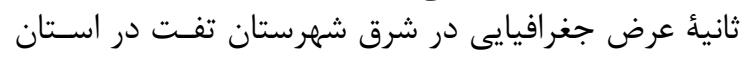

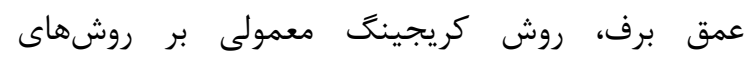

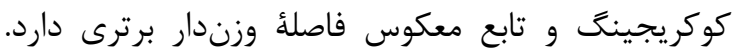

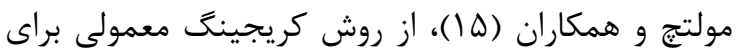

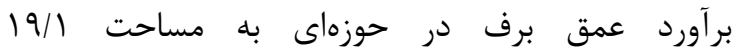

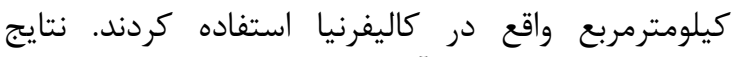

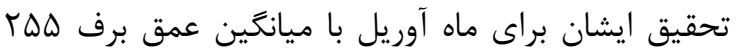

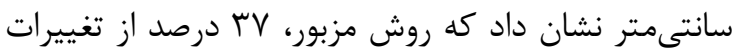

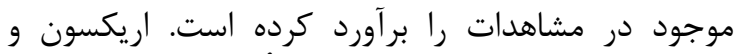

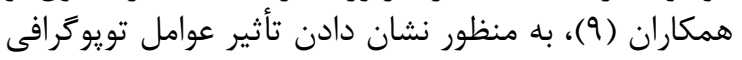

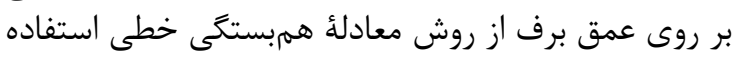

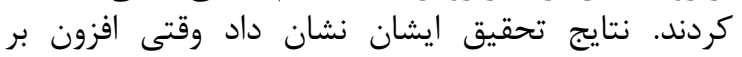

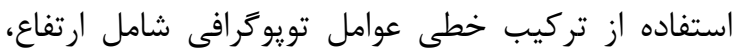

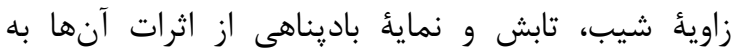

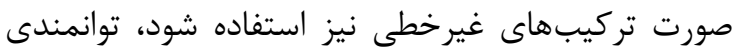

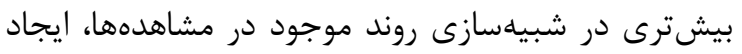

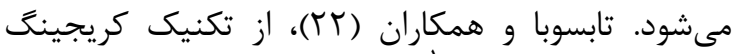

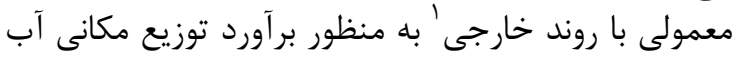

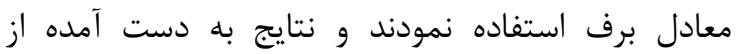

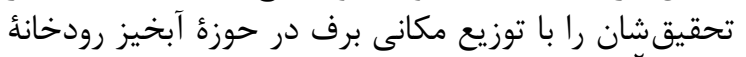

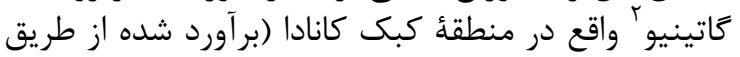

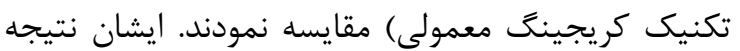

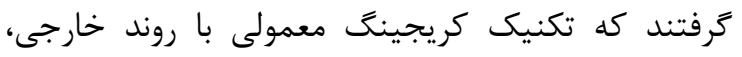

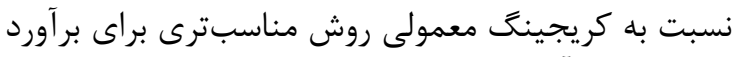

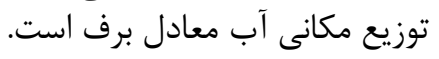

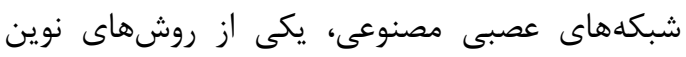

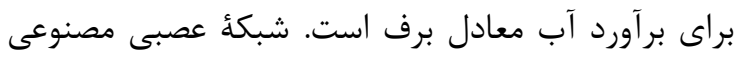

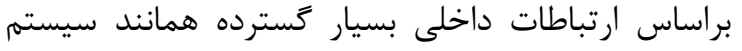

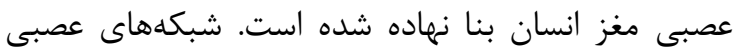

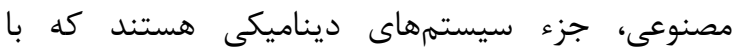

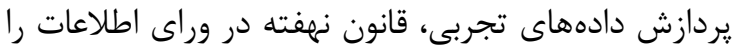

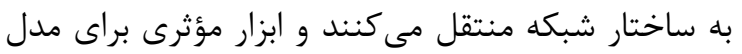

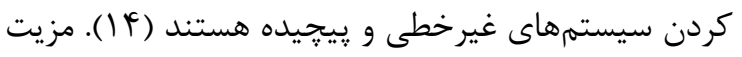

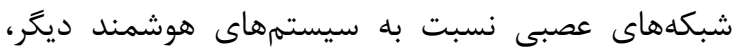

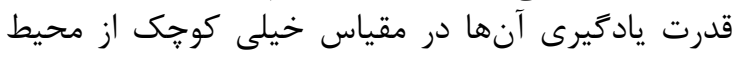

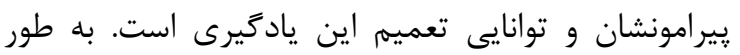

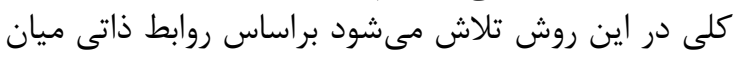

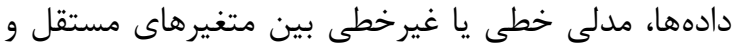

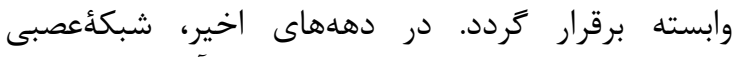

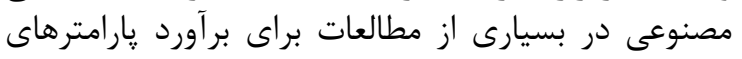

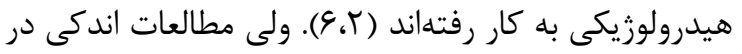

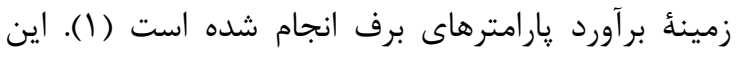

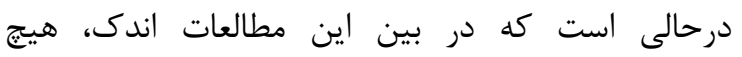
مطالعهاى در مورد برآورد يارامترهاى برف برف با استفاده از إن 


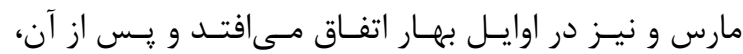

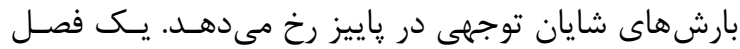

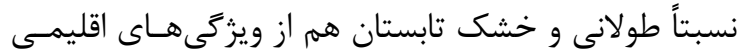

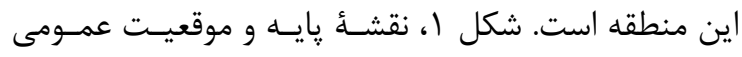

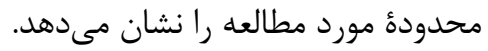

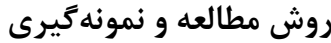

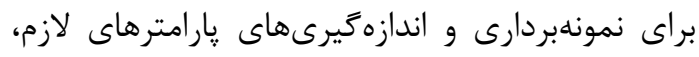

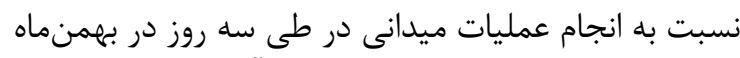

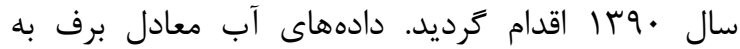

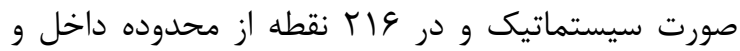

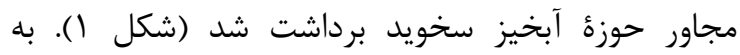

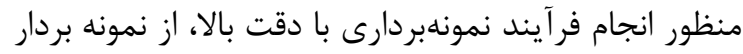

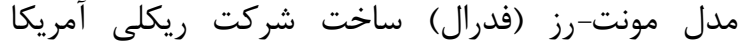

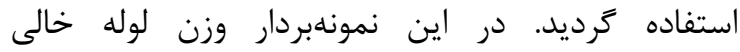

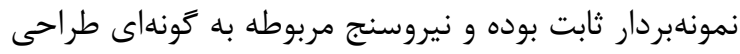

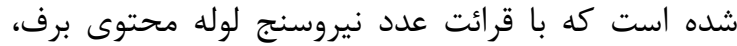

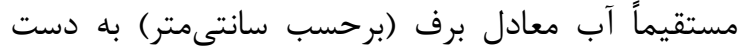

مى آيد (شكل r).

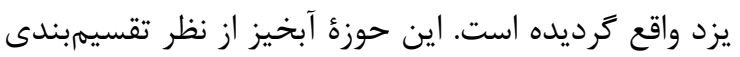

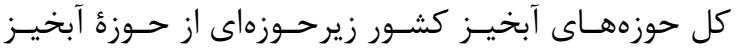

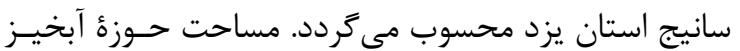

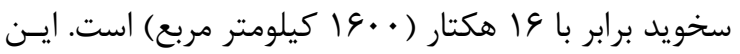

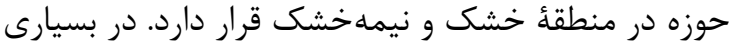

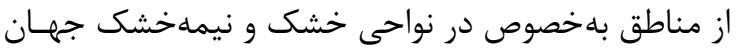

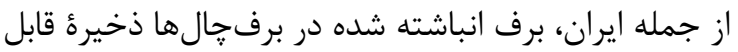

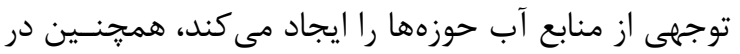

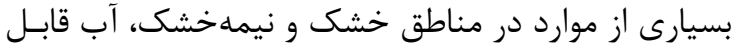

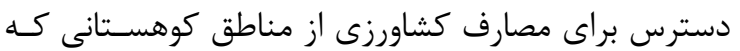

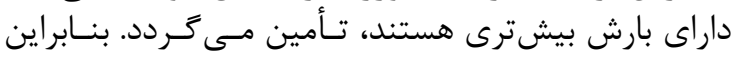

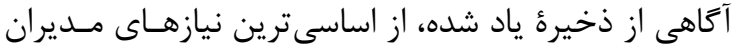

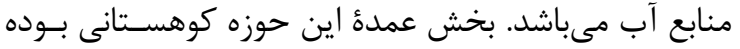

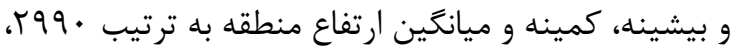

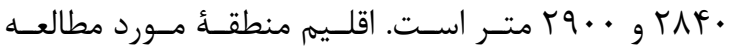

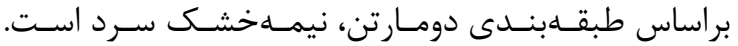

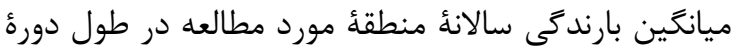

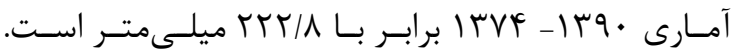

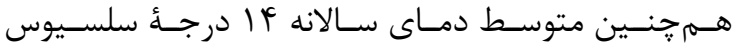
مىباشد. بيشترين بارش هاى منطقه در مـامهـاى فوريـهـ و

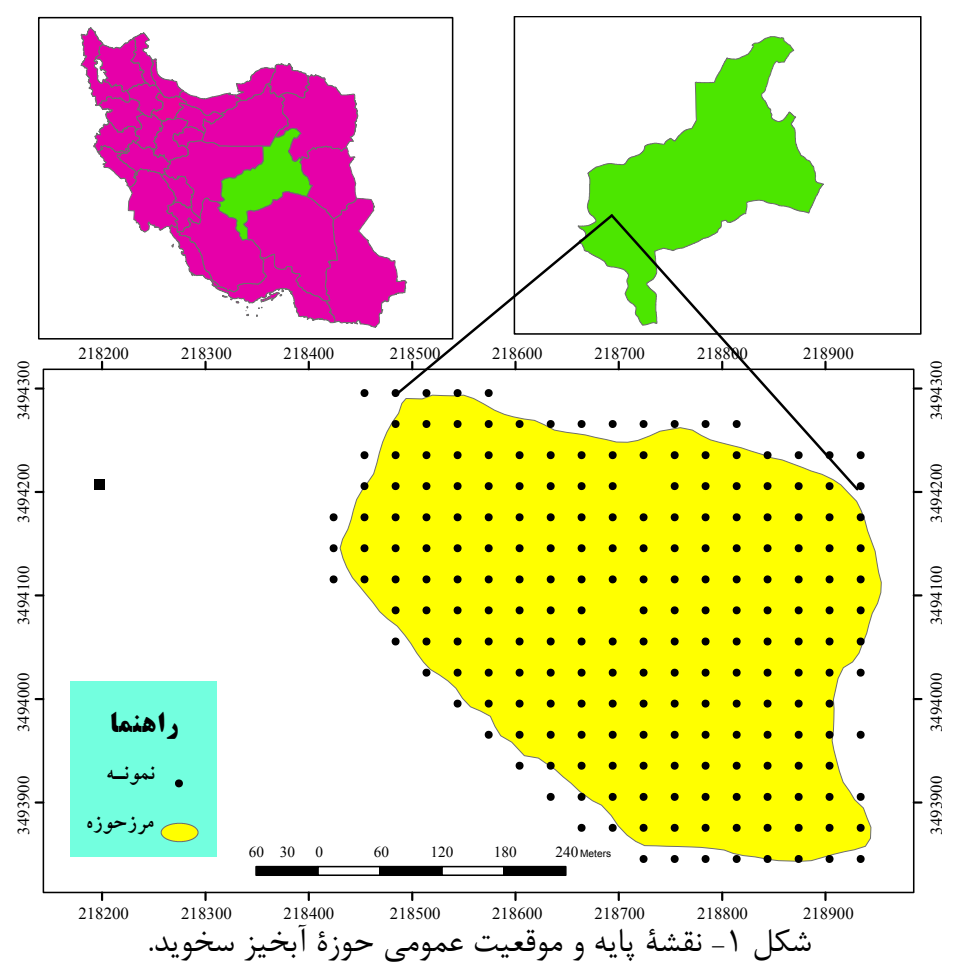




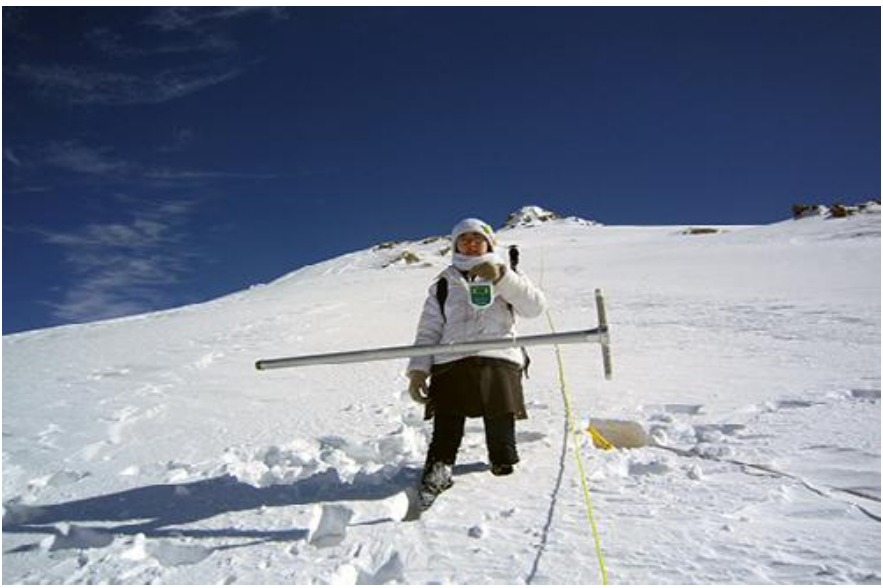

شكل rــ انجام نمونهبردارى با استفاده از نمونهبردار مدل مونت رز.

اطلاعات كمكى براى ورودى شبكة عصبى مصنوعى استفاده گرديد.

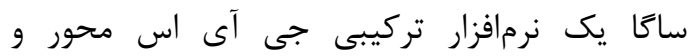

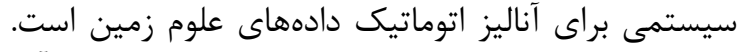

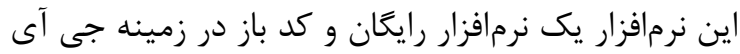

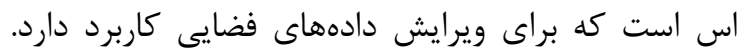

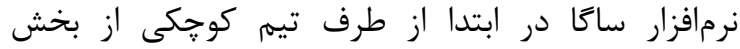

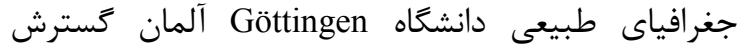
يافت. يارامترهاى زميننماى ذئى ذكر شده در جدول

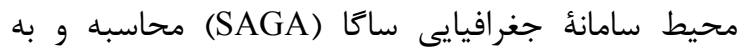

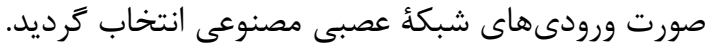

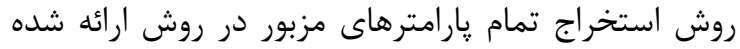

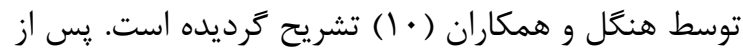

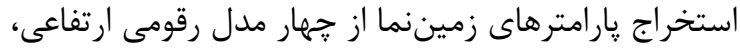

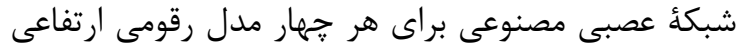

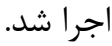

در ادامئ اين تحقيق با روش آزمون و خطا، اقدام به

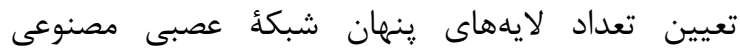

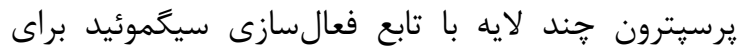

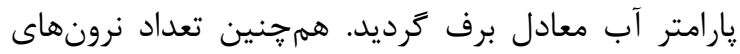

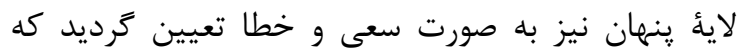

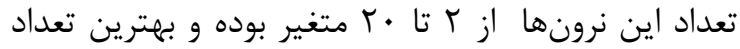

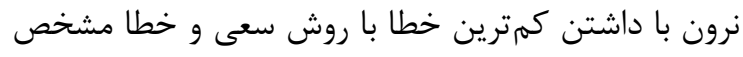

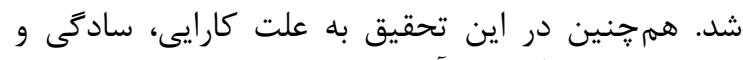

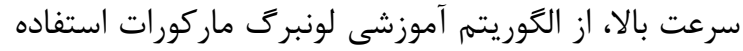

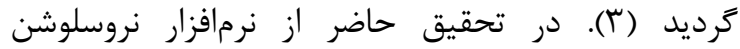
(Neurosolutions-5) و در نهايت شبيهسازى آب معادل برف استفاده گرديد.
نمونهها در شبكهاى به فواصلسه • مترى اندازهخيرى

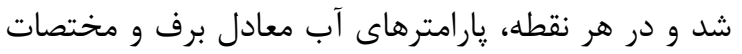

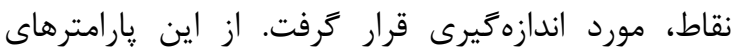

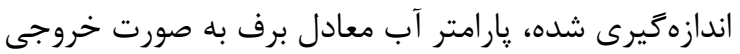

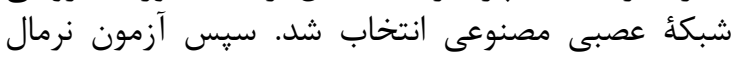

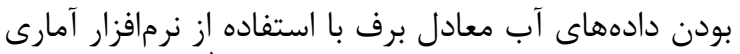
SPSS

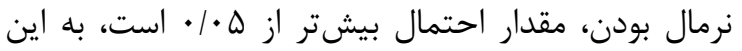

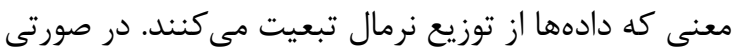

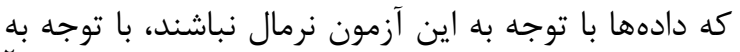

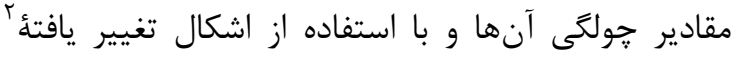

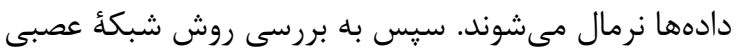

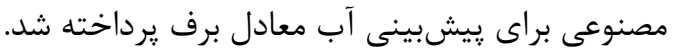

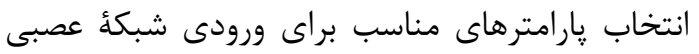

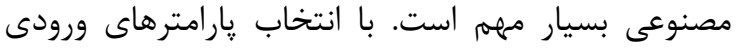

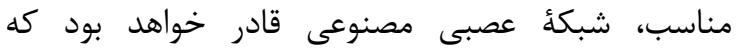

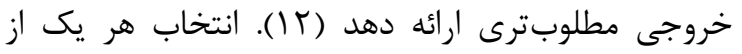
عوامل مؤثر بر توزيع مكانى آب معادل برف، به به ميزان

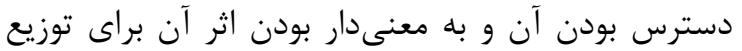

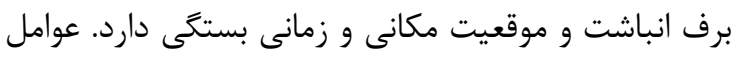

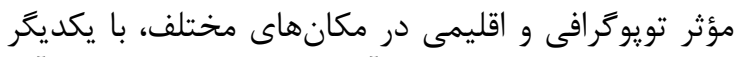

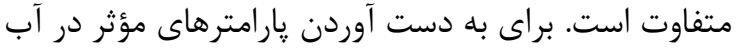

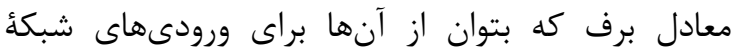

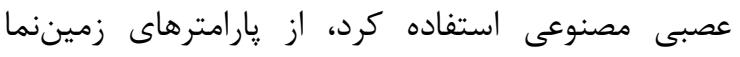

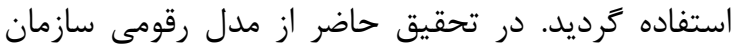

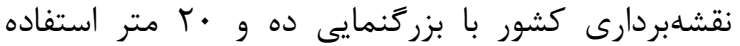

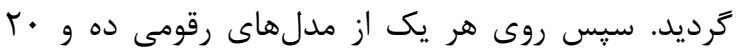

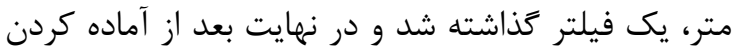
جهار مدل رقومى ارتفاعى، از آنها براى استخراج كردن فئن 
Ifr. يزوهشنامه مديريت حوزه آبخيز سال هفتم/ شماره r|/ بهار و تابستان هوس| ...

\begin{tabular}{|c|c|c|c|}
\hline Input & Row & Input & Row \\
\hline Modified Catchment Area & IV & Cell Balance & 1 \\
\hline MRRTF & 11 & Catchment Slope & r \\
\hline MRVBF & 19 & Channel Network Base Level & r \\
\hline Normalized Height & r. & Catchment Area & i \\
\hline Plan Curvature & rI & Flow Accumulation & $\Delta$ \\
\hline Profile Curvature & tr & Flow Connectivity & 4 \\
\hline Slope & זr & Flow Direction & $\mathrm{v}$ \\
\hline Slope Height & TF & Aspect & $\Lambda$ \\
\hline Standardized Height & ra & Analytical Hillshading & 9 \\
\hline Strahler Order & rq & Curvature Classification & 1 . \\
\hline Stream Power & tr & Altitude Above Channel Network & 11 \\
\hline Valley Depth & ru & Curvature & IT \\
\hline Wetnwss Index & rq & Slope Lenght & זו \\
\hline Wind Effect & r. & Convergence Index & if \\
\hline \multirow[t]{2}{*}{ High } & r & LS Factor & 10 \\
\hline & & Mid Slope Positon & 19 \\
\hline
\end{tabular}

خروجى به تغييرات در يارامترهاى ورودى به كار مئ ميرود.

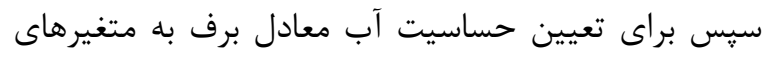

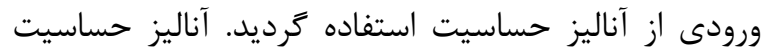

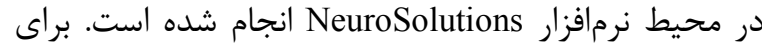

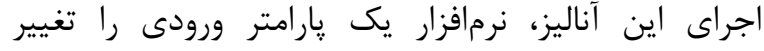

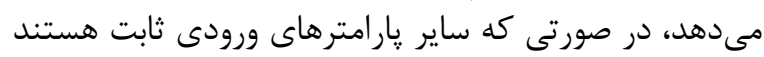

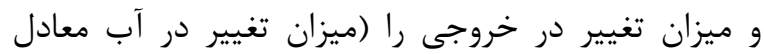

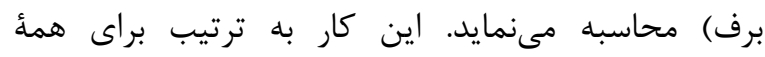

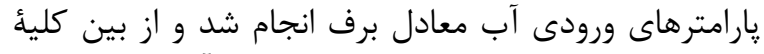

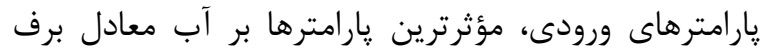

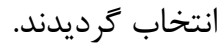

\section{نتايج و بحث}

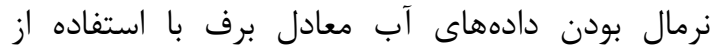

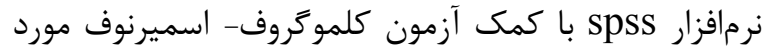

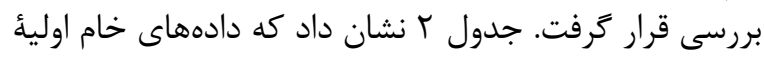

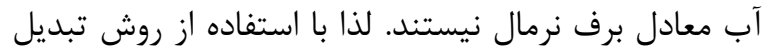

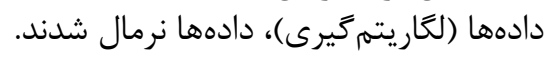

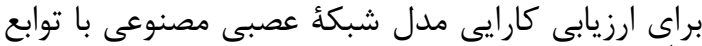

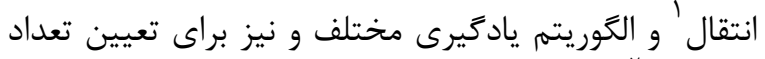

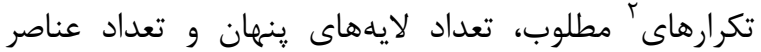

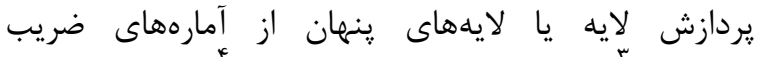

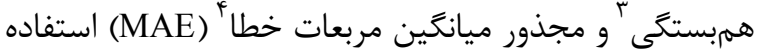
شده كه از روابط زير به دست مين مي آيند:

$r=\frac{\sum\left(X_{i}-\bar{X}\right)\left(Y_{i}-\bar{Y}\right)}{\sqrt{\sum\left(X_{i}-\bar{X}\right)^{2}\left(Y_{i}-\bar{Y}\right)^{2}}}$

(1) (1ابطه (1) - ()

$\mathrm{RMSE}=\sqrt{\frac{1}{n}} \sum_{i=1}^{n}\left(Z_{o}-Z_{p}\right)^{2}$

رابطه (r)

در اين روابط، Y و Y به ترتي شده، و و

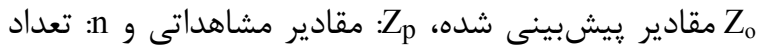

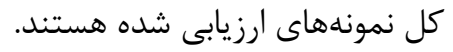
آناليز حساسيت نمونهاي ارزيت

آناليز حساسيت براى تعيين ميزان حساسيت يك پارامتر 


\begin{tabular}{|c|c|c|}
\hline $\mathrm{R}$ & RMSE & 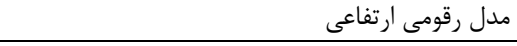 \\
\hline$\cdot$ • re & $\Lambda / \Delta \Delta$ & مدل رقومى ارتفاعى با بزرگنمايى · ل متر \\
\hline - $/ 4 t$ & $G / T V$ & مدل رقومى ارتفاعى با بزرَّنمايى • ا متر فيلتر شده \\
\hline$\cdot \mid 94$ & $\Delta / r \Delta$ & مدل رقومى ارتفاعى با بزرگَنمايى ·· متر \\
\hline$\cdot / V T$ & $F / V V$ & مدل رقومى ارتفاعى با بزركَنمايى ·r متر فيلتر شده \\
\hline
\end{tabular}

\begin{tabular}{|c|c|c|c|c|c|c|c|}
\hline & & & & \multicolumn{4}{|c|}{ جدول ؟- مقادير برخى از آمارههاى آب معادل برف } \\
\hline \multicolumn{2}{|c|}{ آزمون كلموكروف- اسميرنوف } & \multirow{3}{*}{ دامنه } & \multirow{3}{*}{ بيشينه } & \multirow{3}{*}{ كمينه } & \multirow{3}{*}{ 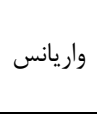 } & \multirow{3}{*}{ ميانگين } & \\
\hline آماره & آماره & & & & & & 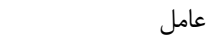 \\
\hline (بعد از تبديل) & (ييش از تبديل) & & & & & & \\
\hline.$/ \cdot 9$ & $\cdot$ & $\Delta F$ & $\Delta 9$ & $\Delta$ & VY/GY & $r \cdot / 9$ & آب معادل برف (cm) \\
\hline
\end{tabular}

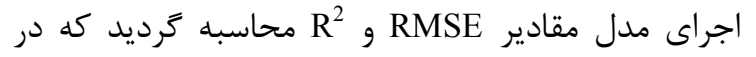

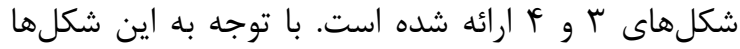

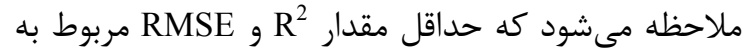

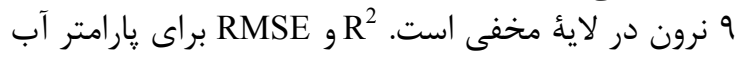

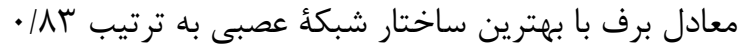

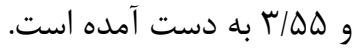

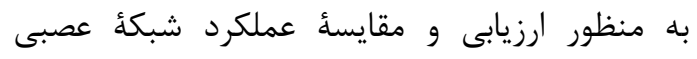

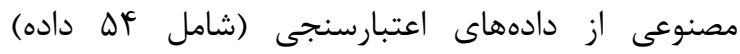

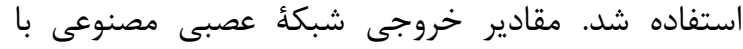

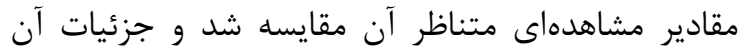

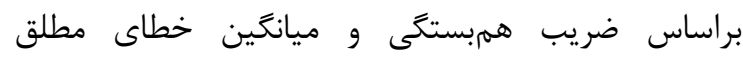

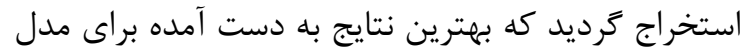

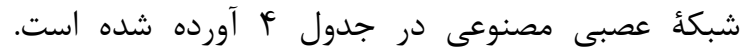

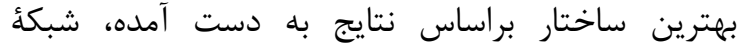

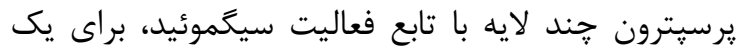

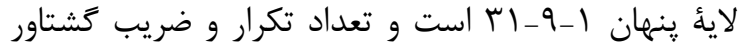

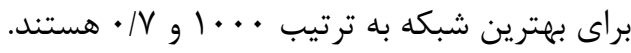

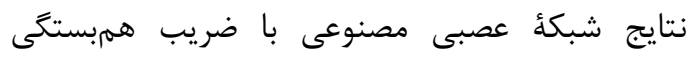

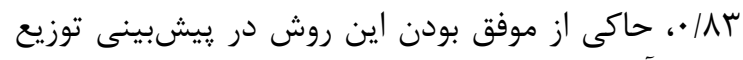

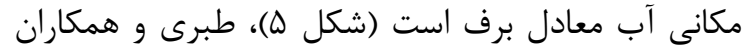

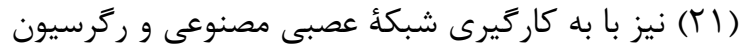

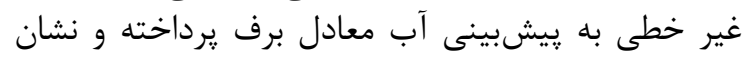

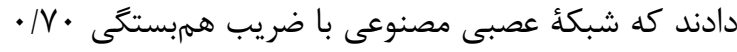

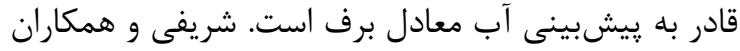

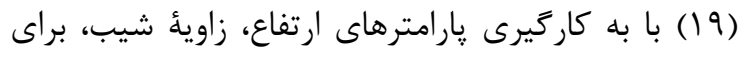

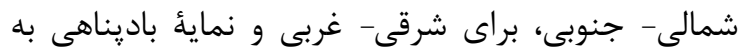

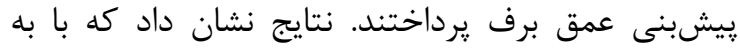

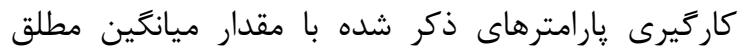

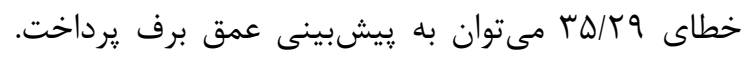

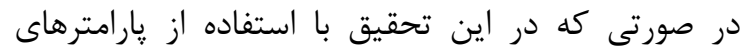
زئومرفومترى، مقدار ميانخين مطلق خطا بسيار كم بوده و

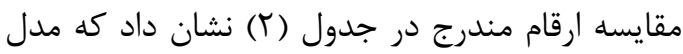

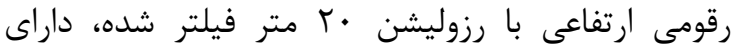

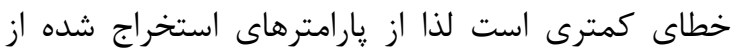

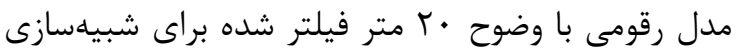

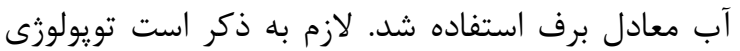

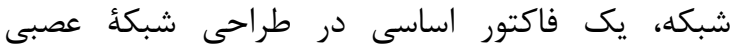

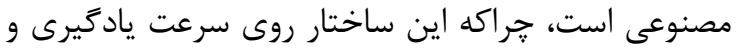

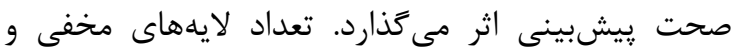

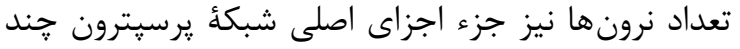

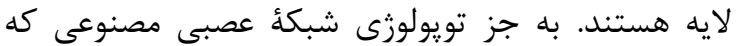

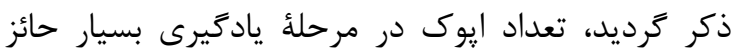

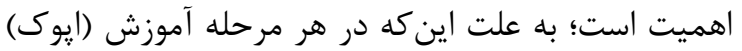

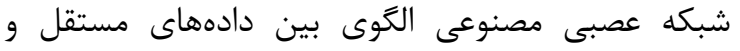

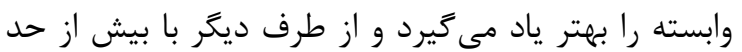

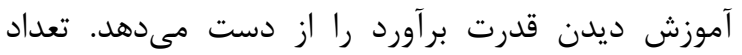

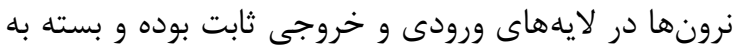

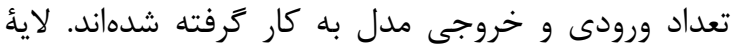

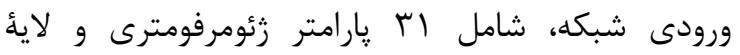

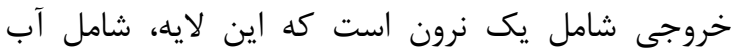

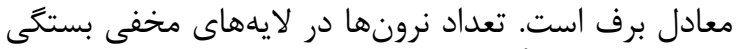

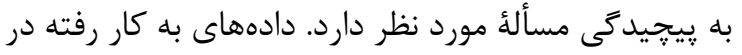

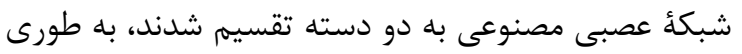

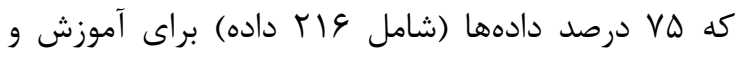

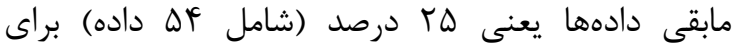

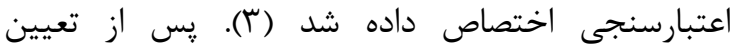

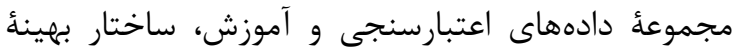

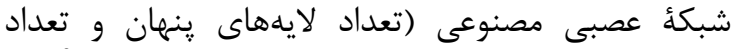

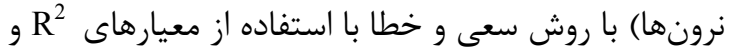

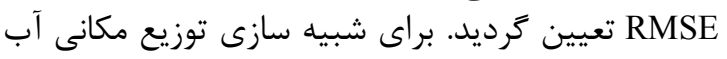

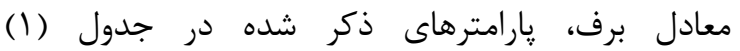

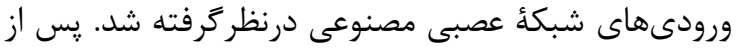




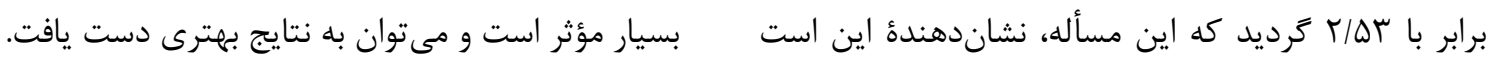

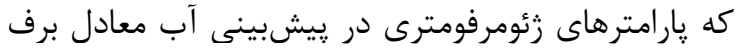

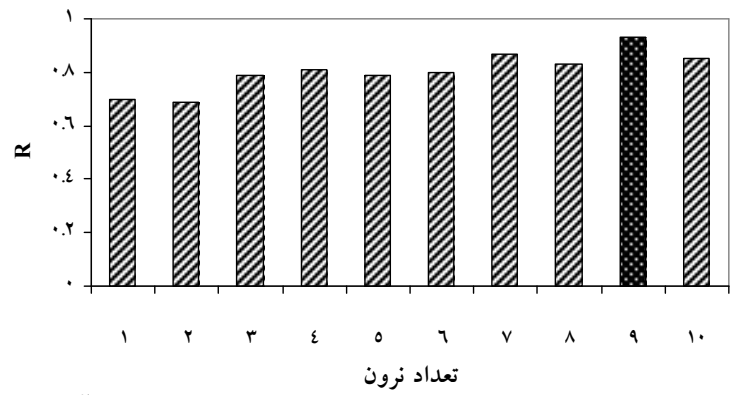

شكل rـ- مقادير R براى تعداد نرون متفاوت در بيشبينى پارامتر آب معادل برف.

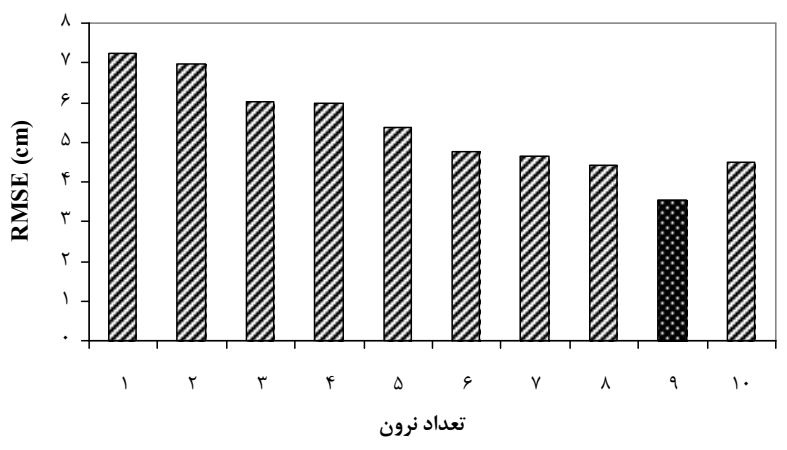

شكل F أ- مقادير RMSE براى تعداد نرون متفاوت در بيشبينى يارامتر آب معادل برف.

\begin{tabular}{|c|c|c|c|c|c|}
\hline & & \multicolumn{4}{|c|}{ جدول F- جزئيات ساختار شبكأ عصبى مصنوعى براى پيشبينى آب معادل برف } \\
\hline MAE & RMSE & $\mathrm{R}^{2}$ & 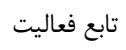 & 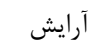 & مدل \\
\hline$r / \Delta T$ & $r / \Delta \Delta$ & - / & سيخموئيد & ||-9|-1 & MLP \\
\hline
\end{tabular}

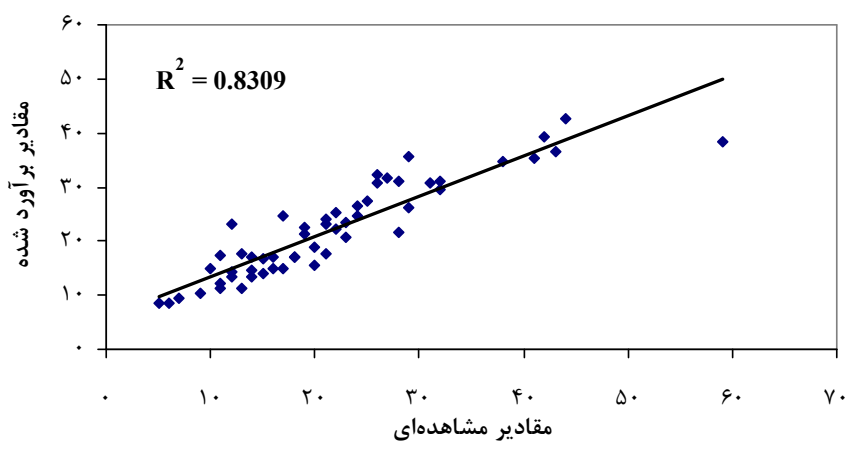

شكل ه- همبستخى مقادير برآورد شده شبكأ عصبى مصنوعى و مقادير مشاهدهاى.

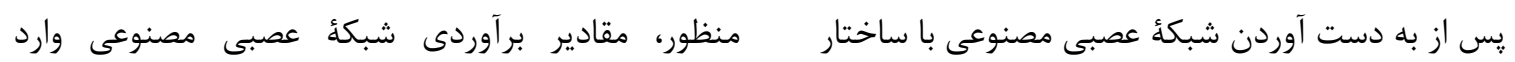

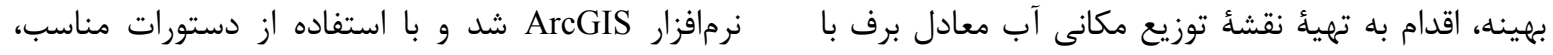

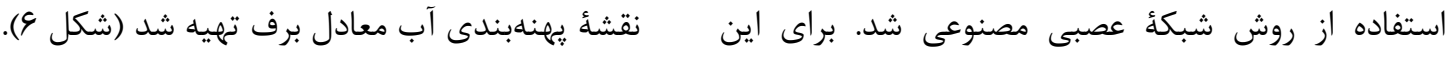




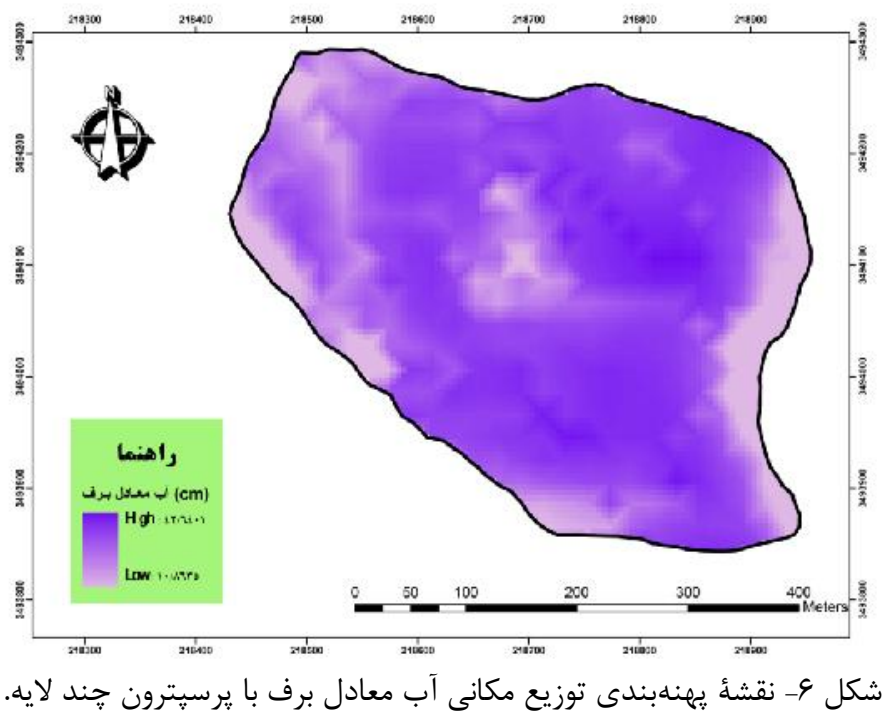

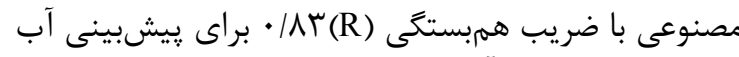

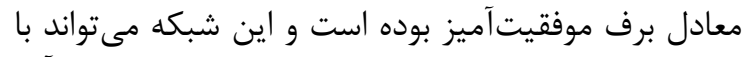

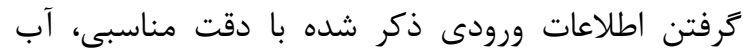

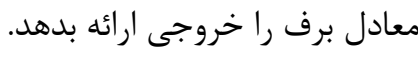

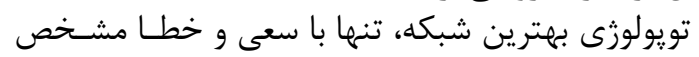

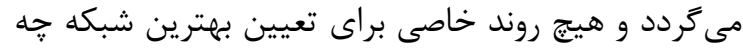

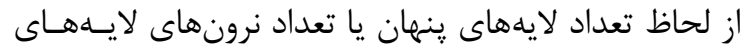

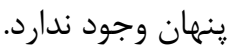

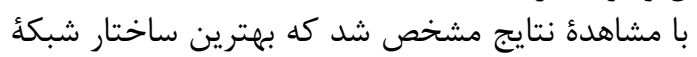

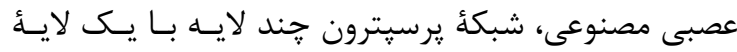

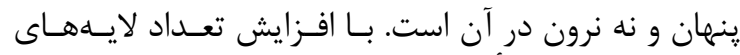

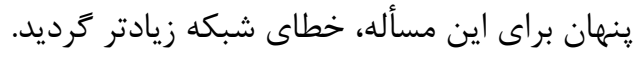

نتايج آناليز حساسيت شبكهُ عصبى مصنوعى نيز نشان

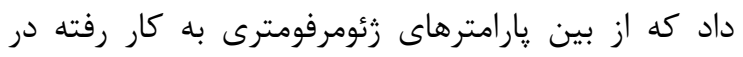

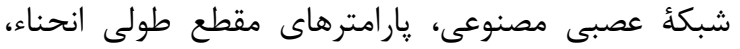

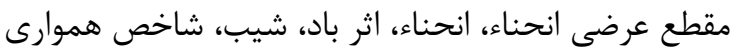

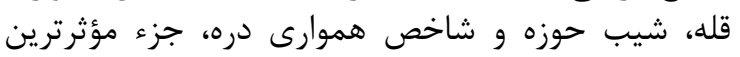

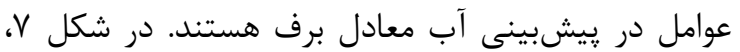
نمودار مؤثرترين عوامل در آب معادي معادل برف نشان شده

در اين تحقيق، روش شبكأ عصبى مصنوعى براى

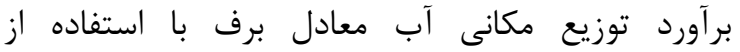

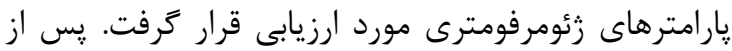

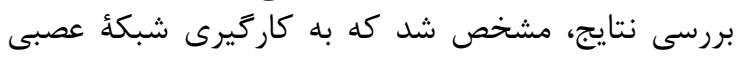

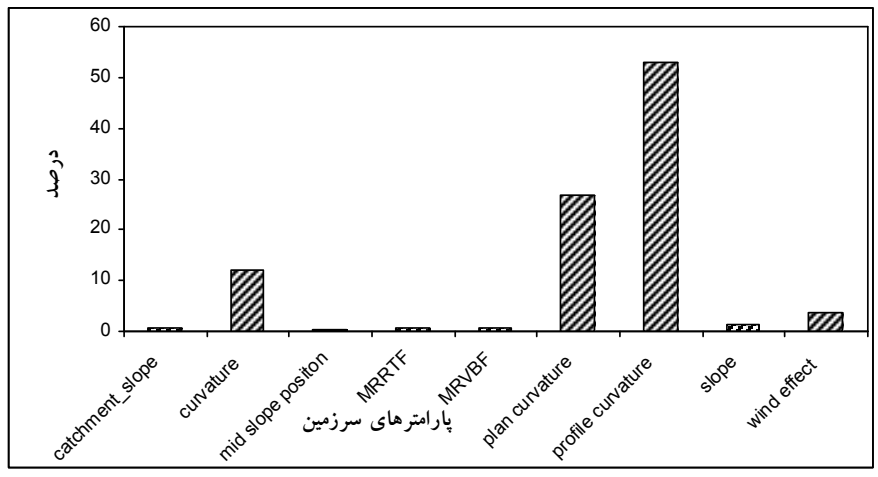

شكل V- مؤثرترين عوامل در پيشبينى آب معادل برف. 
برف و ويزگى هاى آن از جمله آب معادل برف بسيار مؤثر

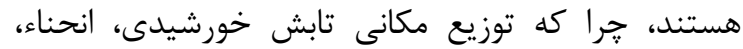

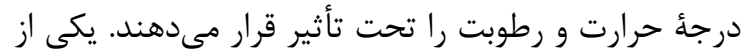

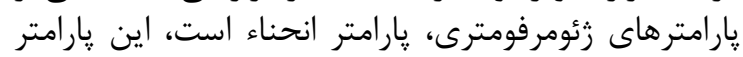

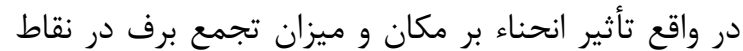

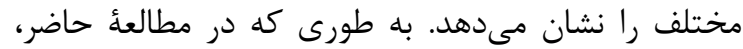

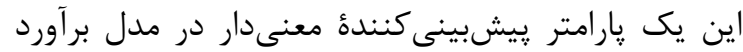

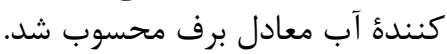

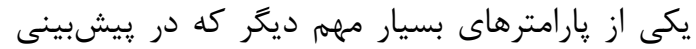

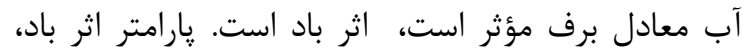

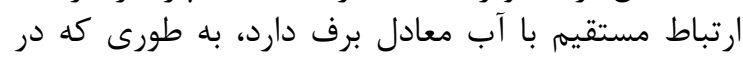

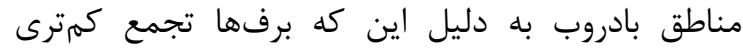

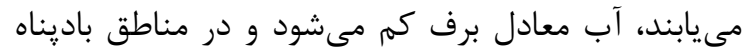

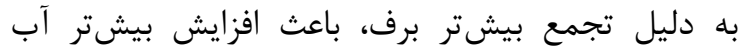

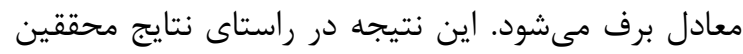

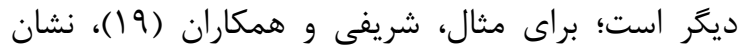

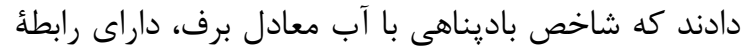

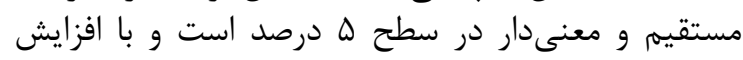

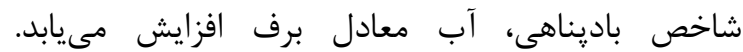

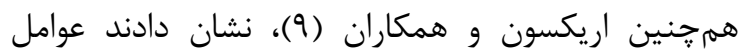

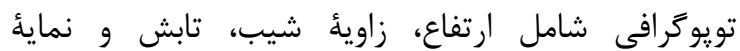

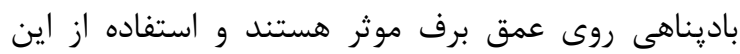
عوامل در شبيهسازى برف بسيار مفيد است.

$$
\begin{aligned}
& \text { به طور كلى، مى توان كفت شبكأ عصبى مصنوعى در اين }
\end{aligned}
$$

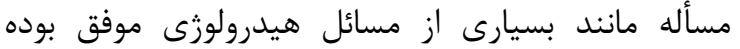

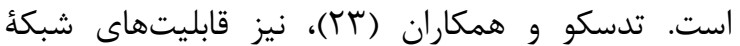

$$
\begin{aligned}
& \text { عصبى مصنوعى در برآورد آب معادل آبران نبر قابليت را مورد تأييد }
\end{aligned}
$$

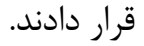

$$
\begin{aligned}
& \text { يس از انجام آناليز حساسيت از طريق شبكأ عصبى برادي }
\end{aligned}
$$

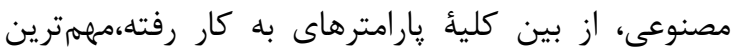

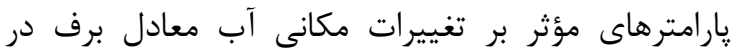

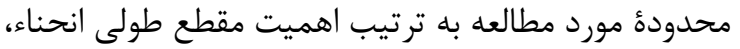

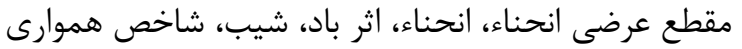

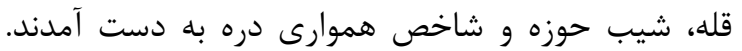

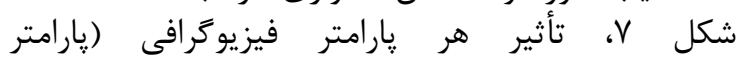

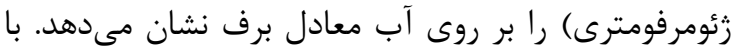

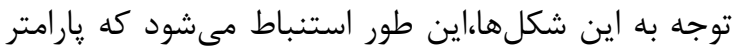

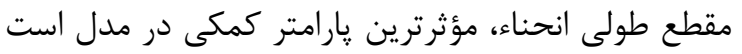

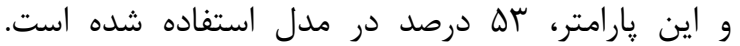

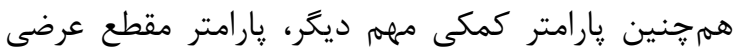

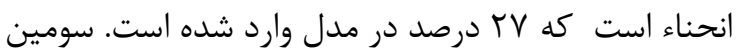

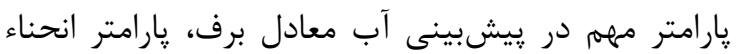

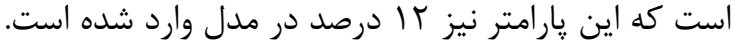

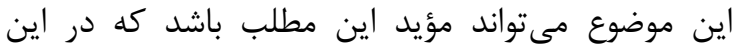

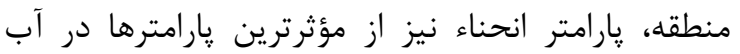

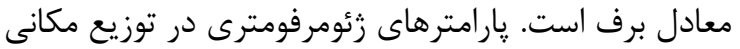

منابع

1. Agarwal, A., S.K. Mishra, S. Ram and J.K. Singh. 2006. Simulation of Runoff and Sediment Yield Using Artificial Neural Networks. Biosystems Engineering, 94: 597-613.

2. Ahmad, S. and S.P. Simonovic. 2005. An Artificial Neural Network Model for Generating Hydrograph from Hydrometeorological Parameters. Journal of Hydrology, 315: 236-251.

3. Amini, M., K.C. Abbaspour, H., Khademi, N. Fathianpour, M. Afyuni and R. Schulin. 2005. Neural Network Models to Predict Cation Exchange Capacity in Arid Regions of Iran. European Journal of Soil Science, 53: 748-757.

4. Bagheri-Fahrji, R. 2011. Estimating the Spatial Distribution of Snow Water Equivalentin Mountain Watersheds Using Geostatistic Methods (Case Study: Bidakhovid), M.Sc. Thesis, Islamic Azad University Maybod branch, $147 \mathrm{pp}$ (In Persian).

5. Bales, R. C. 2007. Field Methods in Snow Hydrology, University of California, Merced. 87 pp.

6. Chen, J. and B.J. Adams. 2006. Integration of Artificial Neural Networks with Conceptual Models in Rainfall-Runoff Modeling. Journal of Hydrology, 318: 232-249.

7. Elder, K.G. Dozier and J. Michaelsen. 1991. Snow Accumulation and Distribution in an Alpine Watershed. Water Resources Research, 27: 1541-1552.

8. Elder, K.R. Rosenthal and R.E. Davis. 1998. Estimating the Spatial Distribution of Snow Water Equivalence in a Mountain watershed. Hydrological Processes, 12: 1793-1808.

9. Erickson, T.A., M.W. Williams and A. Winstral. 2005. Persistence of Topographic Controls on the Spatial Distribution of Snow in Rugged Mountain, Colorado, United States. Water Resources Research, 41: $1-17$.

10. Hengl, T.G., B.M. Huvelink and A. Stein. 2004. A Generic Framework for Spatial Prediction of Soil Variables Based on Regression-kriging. Geoderma, 120: 75-93.

11. Huang, M., G. Peng, J. Zhang and S. Zhang. 2006. Application of Artificial Neural Networks to the Prediction of Dust Storms in Northwest China. Global and Planetary Change, 52: 216-224. 
12. Hosang, J. and K. Dettwiler. 1991. Evaluation of a Water Equivalent of Snow Cover Map in a Small Catchment Area Using a Geostatistical Approach. Hydrological Processes, 5: 283-290.

13. Marchand, W.D. and A. Killingtveit. 2001. Analysis of the Relation between Spatial Snow Distribution and Terrain Characteristics. $58^{\text {th }}$ Estern Snow Conference Ottawa, Ontario, Canada. pp: 71-84.

14. Menhaj, M. 2007. Fundamental of Artificial Neural Networks. Amirkabir Press. 716 pp (In Persian).

15. Molotch, N.P., M.T. Colee, R.C. Bales and J. Dozier. 2005. Estimating the Spatial Distribution of Snow Water Equivalent in an Alpine Basin Using Binary Region Tree Models: the Impact of Digital Elevation Data Independent Variable Selection. Hydrological Processes, 19: 1459-1479.

16. Najafi, M., J. Sheykhiv and J. Porhemat. 2006. Run off from Melting Snow in Snow Areas Using SRM (Case Study Mahabad). Journal of Agricultural Sciences and Natural Resources, 3: 111-121 (In Persian).

17. Potter, T.D. and B.R. Colman. 2003. Handbook of Weather, Climate and Water: Dynamics, Climate, Physical Meteorology, Weather Systems, and Measurements. Wiley-Interscience Press, 1974 pp.

18. Roebber, P.J., S.L. Bruening, D.M. Schultz and J.V. Cortinas. 2002. Improving Snowfall Forecasting By diagnosing Snow Density. Weather and Forecast, 18: 264-287.

19. Sharifi, M.R., M. Akhund-Ali and J. Porhemat. 2007. Assess the Linear Correlation and Ordinary Kriging Method to Estimate the Spatial Distribution of Snow Depth in the Watershed Samsami. Journal of Watershed Management Science \& Engineering, 1: 24-38. (In Persian)

20. Steppuhn, H. 1981. Snow and Agriculture, In Handbook of Snow: Principles, Processes, Management and Use. Blackburn Press, $776 \mathrm{pp}$.

21. Tabari, H., S. Marofi, H. Zare Abyaneh and M.R. Sharifi. 2010. Comparison of Artificial Neural Networks and Combined Models in Estimating Spatial Distribution of Snow Depth and Snow Water Equivalent in Samsami Basin of Iran. Neural Computing Applications, 19: 625-635.

22. Tapsoba, D., V. Fortin, F. Anctil and M. Hache. 2008. Use of the Kriging Technique with External Drift for a Map of the Water Equivalent of Snow: Application to the Gatineau River Basin, Canadian Journal of Civil engendering 32: 289-297.

23. Tedesco, M., J. Pulliainen, M. Takala, M. Hallikainen and P. Pampaloni. 2004. Artificial Neural Network-Based Techniques for the Retrieval of SWE and Snow Depth from SSM/I data. Remote Sensing Environment, 90: 76-85.

24. Tryhorn, L. and A. DeGaetano. 2012. A Methodology for Statistically Downscaling Seasonal Snow Cover Characteristics over the Northeastern United States, International Journal of Climatology, 33: 2728-2743.

25. Vafakhah, M., M. Mohseni Saravi, M. Mahdavi and S.K. AlaviPanah. 2008. Geostatistics Application to Estimate Snow Depth and Density in the Watershed Ourazan. Journal of Watershed Management Science \& Engineering, 4: 49-55 (In Persian).

26. Vaziri, F. 2005. An Applied Hydrology in Iran-The Second Book: Identification of Glaciers in Iran, Management and Planning Organization, Press, $430 \mathrm{pp}$ (In Persian).

27. Zareabyaneh, H. 2012. Estimating the Spatial Distribution of Snow Water Equivalent and Snow Density Using ANN Method (Case Study Watershed Azarbayejan) Journal of Water Resources Engineering, 5: 23-35. 


\title{
Digital Mapping of Snow Water Equivalent using an Artificial Neural Network and Geomorphometric Parameters (Case study: Sakhvid watershed, Yazd)
}

\author{
Somaye Ebdam ${ }^{1}$, Ali Fathzadeh ${ }^{2}$, Rouhollah Taghizadeh-Mehrjardi ${ }^{3}$ and Javad Mahjoobi ${ }^{4}$ \\ 1- Graduated M.Sc. of Watershed Management, Yazd University \\ 2- Associate Professor, Ardakan University (Corresponding Author: fatzade@ardakan.ac.ir) \\ 3- Assistant Professor, Ardakan University \\ 4- M.Sc. of Yazd Province Regional Water Authority \\ Received: October 15, $2013 \quad$ Accepted: November 9, 2014
}

\begin{abstract}
Although a small portion of the Earth's surface is covered by the mountains, but it has a large impact on watershed hydrological perspective Because of the water crisis in arid and semi-arid regions of Iran, monitoring of the amount of snow in these areas is very important. Usually, access to the spatial distribution of snow water equivalent is limited to small scale using sampled data. However, due to the limitations of the mountainous, snow sampling of area is difficult and sometimes impossible in the large basins. Thus, the development of methods in order to estimate snow water equivalent at the un-sampled locations is essential. In this research, an area of 16 ha area in Yazd province was selected and snow water equivalent was measured at 216 points using a Mt. Rose snow sampler. Then the application of artificial neural network method was evaluated using 31 geomorphometric parameters and the digital map of snow water equivalent was obtained. The results showed that the artificial neural network can estimate the snow water equivalent by a $\mathrm{R} 2=0.83$ and RMSE $=3.55$. The results of the sensitivity analysis are also showed that among the ANN parameters used in the prediction of snow water equivalent, Plan Curvature, Profile Curvature, Curvature, Wind Effect, Slope, Multiresolution ridge top flatness index (MRRTF), Catchment slope and Multi resolution index of valley bottom flatness (MRIVBF) are the effective parameters to predict snow water equivalent, respectively.
\end{abstract}

Keywords: Artificial Neural Network, Geomorphometric Parameters, Sakhvid Watershed, Sensitivity Analysis, Snow Water Equivalent 